\title{
APLICAÇ̃̃̃O DA TEORIA DAS DECISÕES A UM PROBLEMA MERCADOLÓGICO
}

\section{PAULO CLARINDO GOLDSCHMIDT}

Sumário: 1. Teoria da probabilidade. 2. Tipos de decisões. 3. Exemplo. 4. Critérios de decisão. 5. Tomacia de decisão em situação de conflito. 6. Conclusão.

Um dos problemas que mais afligem os homens de negócio é o da tomada de decisões. Realmente, é comum verem-se pessoas em conflito, no momento em que surgem à sua frente vários cursos de ação que podem ser seguidos, sem terem plena convicção de qual curso de ação deve ser escolhido.

O objetivo dêste artigo é fornecer um instrumento que possa servir de auxílio quando do surgimento de uma situação dêsse tipo.

Inicialmente, poderíamos estabelecer uma série de premissas para a melhor localização do problema de decisão:

- existem dois ou mais cursos de ação possíveis, que podem ser representados por $\mathbf{S}_{1}, \mathrm{~S}_{2}, \ldots$. $\mathrm{S}_{\mathrm{n}}$. Sòmente um dêstes deve ser seguido, o que equivale a dizer que tais cursos de ação são mùtuamente exclusivos - quando a ocorrência de um dêles exclui a ocorrência dos outros.

- o processo de tomada de decisão irá escolher um dêsses cursos de ação, que deverá ser executado convenientemente.

Paulo Clarindo Goldschmidt - Professor-Contratado do Departamento de Mercadologia da Escola de Administração de Emprêsas de São Paulo, da Fundação Getúlio Vargas.

R. Adm. Emp., Rio de Janeiro, 9 (1): p. 93-104, jan.-mar. 1969 
- a seleção de um determinado curso de ação deve ser feita para se alcançar um objetivo preestabelecido.

Pelo exposto acima, podemos verificar que a pessoa que toma decisões parte de um número qualquer de cursos de ações possiveis até chegar a um curso de ação determinado, com objetivos conhecidos. Torna-se evidente que tal decisão deverá ser tomada, visando-se à otimização dos resultados, seja através de uma função de maximização — como, por exemplo, lucros — seja através de uma função de minimização - como, por exemplo, custos.

Antes, entretanto, de entrarmos na área das decisões pròpriamente ditas, torna-se necessário que façamos uma ligeira introdução a alguns aspectos estatísticos de marcante influência na teoria das decisões. Tais aspectos englobam algumas considerações sôbre a teoria da probabilidade e sôbre a esperança matemática.

1. TEORIA DA PROBABILIDADE

Freqüentemente, problemas empresariais não pertencem à área onde se tem pleno conhecimento de ocorrências futuras. Por exemplo, o administrador mercadológico não tem conhecimento exato de qual será a reação dos consumidores em função de uma modificação nas vias de distribuição de seu produto. Necessitaria, pois, de ter um índice quantitativo que lhe fornecesse uma base para tomar uma decisão racional, ainda que tal índice fôsse apenas uma. aproximação do valor real.

A probabilidade é o instrumento que vem auxiliar na minimização da incerteza associada a um acontecimento. qualquer. A probabilidade pode ser entendida como a frequiência relativa da ocorrência de um acontecimento, caso dada experiência seja repetida um grande número de vêzes. Para tal, supomos que esta experiência permita, além da ocorrência dêsse acontecimento, a ocorrência de uma série de outros, todos mùtuamente exclusivos; isto é, a ocorrência de um acontecimento exclui a possibilidade de ocorrência de qualquer outro acontecimento.

Uma outra maneira de conceituarmos a probabilidade é considerarmos o quociente entre o número de casos favo-. 
ráveis pelo número de casos possíveis. Assim, por exemplo, a probabilidade de ocorrência do acontecimento sair a face 6, em uma jogada de um dado, será: $P$ (face 6) $=1 / 6$, porque temos apenas um caso favorável - saída da face 6 - e seis casos possíveis.

Como podemos deduzir, fàcilmente, $\sum_{i=1}^{n}\left(p_{i}\right)=1$, isto é, a soma das probabilidades é igual a 1 .

1.1. ESPERANÇA MATEMÁtica

Se em uma experiência os acontecimentos possíveis são $a_{1}, a_{2} \ldots a_{n}$, ocorrendo com uma probabilidade $p_{1}, p_{2} \ldots p_{n}$, respectivamente, a esperança matemática é dada por:

$$
E=a_{1} p_{1}+a_{2} p_{2} \ldots+a_{n} p_{n}
$$

ou

$$
\mathrm{E}=\sum_{\mathrm{i}=1}^{\mathrm{n}} \mathrm{a}_{\mathrm{i}} \mathrm{p}_{\mathrm{i}}
$$

Como pode ser visto na fórmula acima, a esperança matemática não é nada mais que uma média aritmética ponderada.

2. TIPOS DE DECISÕES

Voltando ao início do presente artigo, havíamos dito que o homem de negócios possui uma série de cursos de ação referentes ao seu problema de decisão. Além disso, entretanto, existe uma série de ocorrências ambientais que êle não pode controlar, que chamaremos de estados de natureza. Matemàticamente, poderíamos arranjar tal situação em um quadro que denominaremos matriz resultante. Tal matriz pode ser representada da seguinte maneira:

$\begin{array}{ccccr} & \mathrm{N}_{1} & \mathrm{~N}_{2} & \ldots & \mathrm{N}_{\mathrm{j}} \\ \mathrm{S}_{1} & \mathrm{a}_{11} & \mathrm{a}_{12} & \ldots & \mathrm{a}_{1 \mathrm{j}} \\ \mathrm{S}_{2} & \mathrm{a}_{21} & \mathrm{a}_{22} & \ldots & \mathrm{a}_{2 \mathrm{j}} \\ \vdots & \vdots & \vdots & & \vdots \\ \mathrm{S}_{\mathrm{n}} & \mathrm{a}_{\mathrm{n} 1} & \mathrm{a}_{\mathrm{n} 2} & \ldots & \mathrm{a}_{\mathrm{nj}}\end{array}$

onde $S_{1}, S_{2}, \ldots S_{n}$ são cursos de ação e $\mathbf{N}_{1}, \mathbf{N}_{2} \ldots \mathbf{N}_{\mathbf{i}}$, estados de natureza. 
Os valôres de base a dentro da matriz são os valôres resultantes da ocorrência simultânea de uma estratégia com um estado de natureza específico. Assim, por exemplo, o valor de $a_{11}$ será encontrado quando, escolhida a estratégia $S_{1}$, tenha ocorrido um estado de natureza $N_{1}$.

Agora estamos prontos para falar especificamente dos tipos de decisões encontrados, que podemos classificar em três grupos: decisão em clima de certeza, em clima de risco e em clima de incerteza. Para cada um dêles vamos dedicar alguma atenção. Para tanto, vamos trabalhar com um exemplo único, que poderá ser aplicado qualquer que seja o tipo de clima encontrado no momento da decisão.

3. EXEMPLO

A emprêsa $\mathbf{X}$ desenvolveu um produto possuindo três modelos distintos. Por razões financeiras, apenas um dêles pode ser lançado no mercado. Estudos econômicos demonstraram que existem três possibilidades de o produto alcançar os seguintes estágios de participação: até $5 \%$ do mercado total; de 5 a $10 \%$; e de 10 a $20 \%$. O produto não tem nenhuma possibilidade de alcançar uma posição diferente das anteriormente mencionadas. Desta maneira, podemos construir a seguinte matriz:

$\begin{array}{lccc} & \mathrm{N}_{1} & \mathrm{~N}_{2} & \mathrm{~N}_{3} \\ \mathrm{~S}_{1} & \$ 9.000 & \$ 10.000 & \$ 11.000 \\ \mathrm{~S}_{2} & \$ 7.000 & \$ 9.000 & \$ 15.000 \\ \mathrm{~S}_{3} & \$ 3.000 & \$ 13.000 & \$ 12.000\end{array}$

onde

$\mathrm{S}_{1}=$ lançar o modêlo $\mathrm{A}$

$\mathrm{S}_{2}=$ lançar o modêlo $\mathrm{B}$, e

$\mathrm{S}_{3}=$ lançar o modêlo $\mathrm{C}$;

$\mathrm{N}_{1}=$ alcançar participação de até $\mathbf{5} \%$

$\mathrm{N}_{2}=$ alcançar participação de $5 \%$ a $10 \%$, e

$\mathrm{N}_{3}=$ alcançar participação de $10 \%$ a $20 \%$.

Os valôres componentes da matriz representam o lucro total da emprêsa para cada modêlo do produto. Assim, 
de acôrdo com nossa matriz, se o modêlo escolhido para ser lançado no mercado fôsse o modêlo $\mathrm{A}$, caso ocorresse o estado de natureza $N_{1}$, o lucro total seria de $\$ 9.000$. No entanto, na ocorrência de $\mathbf{N}_{2}$, o lucro passaria para .... $\$ 10.000$, e na ocorrência de $N_{3}$, êste seria de $\$ 11.000$.

\section{CRITÉRIOS DE DECISÃO}

\subsection{Clima de Certeza}

Neste clima, o administrador sabe, exatamente, qual estado de natureza irá ocorrer. Suponhamos, no nosso exemplo, que êle tenha certeza absoluta da ocorrência de um dos estados de natureza, digamos $\mathbf{N}_{1}$. Em outras palavras, possivelmente, havia sido feita uma pesquisa de mercado, em que os resultados obtidos afirmavam, com absoluta certeza, que tal modêlo jamais alcançaria $5 \%$ de participação no mercado. Desta forma, nossa matriz inicial se transformaria na seguinte:

$S_{1}$

$\mathrm{N}_{1}$

$\mathbf{S}_{2}$

$\$ 9.000$

$\mathbf{S}_{3}$

$\$ 7.000$

$\$ 3.000$

e a escolha recairia em $S_{1}$, pois é a que apresentaria melhor resultado para a emprêsa.

\subsection{Clima de Risco}

O resultado da pesquisa poderia demonstrar - o que é mais provável - que existem possibilidades de ocorrência de todos os estados de natureza. Assim, de acôrdo com a pesquisa, $\mathbf{N}_{1}$ poderia ocorrer com uma probabilidade de $50 \%, \mathrm{~N}_{2}$ com uma probabilidade de $40 \%$ e $\mathrm{N}_{2}$ com uma probabilidade de $10 \%$. Nossa matriz, então, seria:

$\begin{array}{cccc} & \mathrm{N}_{1} & \mathrm{~N}_{2} & \mathrm{~N}_{3} \\ \text { Probabilidade } & 0,50 & 0,40 & 0,10 \\ \mathrm{~S}_{1} & \$ 9.000 & \$ 10.000 & \$ 11.000 \\ \mathrm{~S}_{2} & \$ 7.000 & \$ 9.000 & \$ 15.000 \\ \mathrm{~S}_{3} & \$ 3.000 & \$ 13.000 & \$ 12.000\end{array}$


Aplicando-se a esperança matemática, obteríamos:

$$
\begin{aligned}
& S_{1}=(9.000 \times 0,50)+(10.000 \times 0,40)+(11.000 \times 0,10)=9.600 \\
& S_{2}=(7.000 \times 0,50)+(9.000 \times 0,40)+(15.000 \times 0,10)=8.600 \\
& S_{3}=(3.000 \times 0,50)+(13.000 \times 0,40)+(12.000 \times 0,10)=7.900
\end{aligned}
$$

Desta forma, a escolha recairia em $S_{1}$, pois esta estratégia apresentaria o maior valor esperado para a emprêsa.

\subsection{Clima de Incerteza}

No clima de incerteza, tomada de decisão é bem mais difícil. Suponhamos, em nosso exemplo, que nenhuma pesquisa tenha sido feita; portanto, o administrador não tem conhecimento algum sôbre as possibilidades do produto no mercado, e, no entanto, deve tomar uma decisão. Esta será função de uma série de critérios, que enumeraremos a seguir.

4.3.1. Critério de Pessimismo. Êste critério sugere que o administrador deve ser completamente pessimista. A decisão a ser tomada deve basear-se nas piores consequiências de cada uma das estratégias, e, destas, deve ser escolhida a melhor. Assim, escolhendo-se $S_{1}$, a pior consequiência seria o valor de $\$ 9.000$, caso ocorresse $\mathrm{N}_{1}$; escolhendo-se $S_{2}$, a pior conseqüência seria o valor $\$ 7.000$, na ocorrência de $N_{1}$; na escolha de $S_{3}$, a pior conseqüência seria o valor de $\$ 3.000$, ainda com a ocorrência de $\mathbf{N}_{1}$. Nossa matriz então seria:

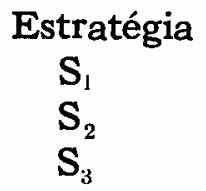

Pior Resultado
$\$ 9.000$
$\$ 7.000$
$\$ 3.000$

$O$ administrador deve, pois, escolher $S_{1}$, porque, na pior das hipóteses, seu lucro será de $\$ 9.000$. Em outras palavras, neste caso, êle deve escolher o critério maximum, isto é, escolher o maior valor dentre os menores.

4.3.2. Critério de Otimismo. Êste critério situa-se no extremo oposto ao anterior. Por alguma razão, que não vamos comentar neste artigo, o administrador sente que as 
melhores possibilidades vão ocorrer. Sua decisão será escolher a melhor estratégia dentre as melhores existentes. Assim, o administrador teria:

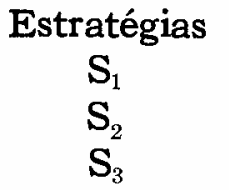

Melhores Resultados

$\$ 11.000$

$\$ 15.000 \leftarrow$

$\$ 13.000$

A escolha recairia em $S_{2}$, pois é o melhor resultado entre os melhores. Em outras palavras, êle escolheria a estratégia máxima. $\mathrm{Na}$ realidade, nenhum administrador é completamente otimista. Para tornar essa decisão mais racional, foi criado um coeficiente de otimismo, que é uma probabilidade subjetiva que o administrador dá à ocorrência dêsse critério, comparada com uma probabilidade subjetiva de ocorrência do critério de pessimismo. A probabilidade de ocorrência do critério de pessimismo é o complemento da probabilidade subjetiva de ocorrência do critério de otimismo. Se chamarmos de $\mathrm{x}$ a probabilidade subjetiva de ocorrência do critério de otimismo, (1-x) será a probabilidade de ocorrência do critério de pessimismo. Se, no nosso exemplo, o administrador desejasse utilizar o critério de otimismo com um coeficiente de otimismo de $60 \%$, teríamos:

Probabilidade

Critério Otimista Critério Pessimista

$\begin{array}{lll}\mathrm{S}_{1} & \$ 11.000 & \$ 9.000 \\ \mathrm{~S}_{2} & \$ 15.000 & \$ 7.000 \\ \mathrm{~S}_{3} & \$ 13.000 & \$ 3.000\end{array}$

Aplicando-se a esperança matemática teremos:

$\mathrm{S}_{1}=(0,60 \times \$ 11.000)+(0,40 \times \$ 9.000)=\$ 10.200$

$\mathrm{S}_{2}=(0,60 \times \$ 15.000)+(0,40 \times \$ 7.000)=\$ 11.800 \leftarrow$

$\mathrm{S}_{3}=(0,60 \times \$ 13.000)+(0,40 \times \$ 3.000)=\$ 900$

A escolha recairá em $S_{2}$, que dá a maior esperança matemática. Pode-se notar, fàcilmente, que quando o coeficiente de otimismo é igual a zero, caímos no caso do critério de pessimismo; quando o coeficiente de pessimismo é igual a zero, caímos no critério de otimismo puro. 
4.3.3. Critério de Pesar. Suponhamos que o nosso administrador tenha escolhido uma estratégia qualquer. Após a ocorrência do estado de natureza, nosso administrador pode estar pesaroso, pôsto que êle não escolheu a melhor estratégia disponível. No exemplo, vamos supor que ocorreu o estado de natureza $N_{1}$. Se o administrador tivesse escolhido $S_{1}$, êle não sentiria nenhum pesar porque teria Escolhido a estratégia que lhe oferecia o melhor resultado. No entanto, caso a escolha tivesse recaído em $\mathbf{S}_{2}$, êle teria perdido $\$ 9.000-\$ 7.000=\$ 2.000$, índice de pesar que êle sente por não ter escolhido $S_{1}$. Se $S_{3}$ fôsse escolhido, êle teria sentido um pesar de $\$ 9.000-\$ 3.000=\$ 6.000$. Desta maneira, podemos construir a seguinte matriz de pesar:

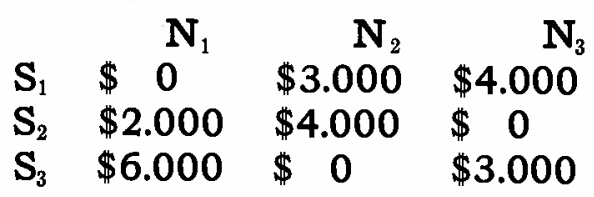

Esste critério é uma variante do critério de pessimismo, isto é, o administrador vai escolher a melhor dentre as piores conseqüências. Assim teremos:

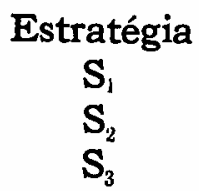

Maior Pesar
$\$ 4.000 \leftarrow$
$\$ 4.000 \leftarrow$
$\$ 6.000$

A escolha recairá em $S_{1}$ ou $S_{2}$ estratégias que minimizam os maiores pesares que o administrador pode sentir.

4.3.4. Critério Subjetivista. Êste critério é baseado no princípio da razão insuficiente. Segundo êste princípio, desde que não haja nenhuma razão para se acreditar que a probabilidade de ocorrência de um estado de natureza é diferente da probabilidade de ocorrência de outro, então devemos presumi-las iguais. No nosso exemplo, teríamos:

$$
P\left(N_{1}\right)=P\left(N_{2}\right)=P\left(N_{3}\right)=\frac{1}{n} \sum_{i=1}^{n} P_{i} \text { ou }
$$




$$
\mathbf{P}\left(\mathbf{N}_{1}\right)=\mathbf{P}\left(\mathbf{N}_{2}\right)=\mathbf{P}\left(\mathbf{N}_{3}\right)=\frac{1}{3}
$$

Desta forma, êsse critério passaria a ser igual ao clima de risco, isto é,

Probabilidade

$$
\mathrm{N}_{1}
$$

$\mathrm{N}_{2}$

$\mathbf{N}_{3}$

$\begin{array}{llll}\mathrm{S}_{1} & \$ 9.000 & \$ 10.000 & \$ 11.000 \\ \mathrm{~S}_{2} & \$ 7.000 & \$ 9.000 & \$ 15.000 \\ \mathrm{~S}_{3} & \$ 3.000 & \$ 13.000 & \$ 12.000\end{array}$

Calculando-se a esperança matemática, teríamos :

$$
\begin{aligned}
& S_{1}=\left(\$ 9.000 \times \frac{1}{3}\right)+\left(\$ 10.000 \times \frac{1}{3}\right)+\left(11.000 \times \frac{1}{3}\right)=\$ 10.000 \\
& S_{2}=\left(\$ 7.000 \times \frac{1}{3}\right)+\left(\$ 9.000 \times \frac{1}{3}\right)+\left(15.000 \times \frac{1}{3}\right)=\$ 10.333 \\
& S_{3}=\left(\$ 3.000 \times \frac{1}{3}\right)+\left(\$ 13.000 \times \frac{1}{3}\right)+\left(12.000 \times \frac{1}{3}\right)=\$ 9.333
\end{aligned}
$$

A escolha recairá em $S_{2}$, que dá a maior esperança matemática.

5. TOMAda de decisão em SituaÇÃo de CONFLito

Como um caso especial, vamos considerar a tomada de decisão em clima de conflito.

Nas situações vistas anteriormente, o administrador defrontava-se com estados de natureza sôbre os quais, como já vimos, êle não possui nenhum poder de contrôle. Além disso, os estados de natureza não têm qualquer dose de racionalidade, isto é, a sua ocorrência independe da estratégia escolhida pela pessoa que tomou a decisão. Entretanto, tal fato não ocorre quando existem opositores racionais. Neste caso, o opositor racional pensará, detalhadamente, antes de tomar sua própria decisão sôbre o que poderá fazer seu concorrente. Na teoria das decisóes, tal situação é explicada pela teoria dos jogos. 
Tal teoria se baseia no conflito de interêsses entre os participantes, pôsto que se supõe que cada um deseja frustrar os desejos do outro.

Vamos imaginar o tipo mais simples de um jôgo, que se caracteriza por apenas dois participantes. Diz-se que um jôgo é de soma-zero quando o ganho de um participante é exatamente igual à perda do outro. Quando tal fato não ocorre, diz-se que o jôgo é de soma-não-zero.

Tal como fizemos com os estados de natureza, podemos construir uma matriz tendo como única modificação a substituição dos $\mathrm{N}_{\mathrm{s}}$, estados da natureza, por $\mathrm{C}_{\mathrm{s}}$, ações dos competidores. Assim, teremos:

$\begin{array}{lcccc} & C_{1} & C_{2} & \ldots & C_{j} \\ S_{1} & a_{11} & a_{12} & \ldots & a_{1 j} \\ S_{2} & a_{21} & a_{22} & \ldots & a_{2 j} \\ \vdots & \vdots & \vdots & & \vdots \\ S^{n} & a_{n 1} & a_{n 2} & \ldots & a_{n j}\end{array}$

onde $S_{1}, S_{2} \ldots S_{n}$ são as estratégias de um dos concorrentes; $\mathrm{C}_{1}, \mathrm{C}_{2} \ldots \mathrm{C}_{\mathrm{j}}$, as do outro; $\mathrm{e} \mathrm{a}_{\mathrm{ij}}$, o resultado da escolha $i$ de um concorrente, juntamente com a escolha $j$ do outro.

Vamos tomar, como exemplo, uma situação de conflito caracterizada pela existência de apenas dois concorrentes, onde se observa a ocorrência de um jôgo de soma-zero. Suponhamos uma emprêsa que esteja disputando a posição no mercado com um único concorrente, ambos fabricando o mesmo produto. Cada emprêsa possui quatro estratégias - evidentemente, não é necessário que o número de estratégias seja o mesmo para cada concorrente - que são demonstradas na matriz que se segue:

$\begin{array}{ccccc} & \mathrm{C}_{1} & \mathrm{C}_{2} & \mathrm{C}_{3} & \mathrm{C}_{4} \\ \mathrm{~S}_{1} & 5 & -2 & 0 & -4 \\ \mathrm{~S}_{2} & -4 & 1 & 1 & -1 \\ \mathrm{~S}_{3} & 3 & 4 & 2 & 3 \\ \mathrm{~S}_{4} & 3 & -4 & 1 & -5\end{array}$


Os valôres dentro da matriz representam modificações percentuais de participação no mercado. Assim, se um concorrente escolhe $S_{1}$ e o outro escolhe $C_{1}$, o primeiro aumenta sua participação no mercado em $5 \%$, enquanto o segundo vê sua participação reduzida do mesmo valor, porque se trata de um jôgo de soma-zero. Caso o primeiro concorrente mantenha sua escolha e o segundo opte pela alternativa $C_{2}$, então, aquêle diminuirá sua participação em $2 \%$ - porque valôres negativos significam perda para êle - enquan. to êste aumentaria sua participação do mesmo valor.

Vejamos, pois, qual deve ser o comportamento de cada um dos concorrentes. Neste tipo de situação, o único critério dos concorrentes racionais é o de pessimismo. No caso do primeiro concorrente, teríamos:

Estratégias

$\mathrm{S}_{1}$

$\mathrm{S}_{2}$

$\mathrm{S}_{3}$

$\mathrm{S}_{4}$
Piores Conseqüências

-4
-4
2
-5

De acôrdo com o critério de pessimismo, êle escolheria a estratégia $S_{3}$ que é a melhor consequiência entre as piores possíveis, isto é, êle ganharia $2 \%$ de participação no mercado.

Porém, o concorrente também é racional e, por conseguinte, vai decidir dentro do mesmo critério. Então, teríamos:

Estratégias

$\mathbf{C}_{1}$

$\mathrm{C}_{2}$

$\mathrm{C}_{3}$

$\mathrm{C}_{4}$
Piores Conseqüuências

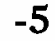

$-4$

$-2$

$-3$

Êle escolheria a estratégia $\mathrm{C}_{3}$ que é a melhor conseqüência entre as piores possíveis, isto é, êle perderia $2 \%$ de participação no mercado. Assim, a conseqüência das decisões dos concorrentes será um acréscimo da participação, no mercado, de $2 \%$ para o primeiro e um decréscimo, do mesmo valor, na participação do segundo. Qualquer outra estraté- 
gia que $\mathrm{C}$ escolhesse iria levar a um resultado pior que o anteriormente obtido. Assim, se êle escolhesse $\mathrm{C}_{1}$, poderia perder até $5 \%$, caso o concorrente escolhesse $S_{1}$; se escolhesse $\mathrm{C}_{2}$, até $4 \%$, caso $\mathrm{S}_{3}$ fôsse a escolha do concorrente; e se escolhesse $\mathrm{C}_{4}$, até $3 \%$, caso $\mathrm{S}_{3}$ fôsse escolhida pelo concorrente. Logo, êle escolheria $\mathrm{C}_{3}$. O mesmo raciocínio é válido para $S$. Se êle escolhesse $S_{1}$, poderia perder até $4 \%$, se o concorrente escolhesse $C^{4}$. Se escolhesse $S_{2}$, até $4 \%$, caso $C_{1}$ fôsse escolhida e se escolhesse $S_{4}$, até $5 \%$, se $\mathrm{C}_{4}$ fôsse a escolha. Portanto, a escolha que oferece melhor resultado para ambos é $S_{3}$ para o primeiro concorrente e $\mathrm{C}_{3}$ para o segundo, isto é, ambos os concorrentes escoIhem suas estratégias pelo critério de pessimismo.

6. CONCLUSÃo

E-nos difícil dizer exatamente qual critério deve ser utilizado pelo administrador responsável pela tomada de decisões. Com exceção, é claro, dos climas de certeza e de risco, não podemos afirmar que um critério é superior a outro. Isto vai depender quase que exclusivamente de condiçóes subjetivas da pessoa que toma uma decisão. Porém, é fácil de se perceberem situações em que o administrador possui algum sentimento do que possa vir a ocorrer, e, portanto, sua decisão deve basear-se neste fato. As aplicações dentro da área mercadológica são inúmeras, e dentre elas podemos citar: lançamento de um nôvo produto no mercado, determinação do melhor preço de um produto, seleção de canais de distribuição, seleção da melhor média, escolha da meIhor estratégia promocional, seleção do alvo mercadológico, etc.

\section{BIBLIOGRAFIA}

Miller D. W. e StARR, M. K. The Structure of Human Decisions, Nova Jersey, Prentice-Hall, Inc., 1967.

Pessemier, E. A. New Product Decisions, Nova Iorque, McGraw-Hill Book Co., 1966.

Srmon, H. A. A Capacidade de Decisão e de Liderança, Editôra Fundo de Cultura, 1963.

Bross, I. D. J. Design for Decision, Nova Iorque, The MacMillan Co., 1953. LuCE, R. D. e RAIffA, H. Games and Decision, Nova Iorque, John Wiley \& Sons, Inc., 1958. 